\title{
Response to: Evidence-Based of Nonoperative Treatment in Adolescent Idiopathic Scoliosis
}

\author{
Hak-Sun Kim \\ Department of Orthopedic Surgery, Gangnam Severance Spine Hospital, Yonsei University College of Medicine, Seoul, Korea
}

1. The Risser sign is used as a standard criterion in the treatment of scoliosis because it represents the velocity of height growth. Gender plays a role in the Risser stages. For example, female adolescents in Risser stage 1 have already passed the peak high velocity (PHV); therefore for female adolescents at Risser stage 1 or 2 with 20 degrees Cobb's angle, I recommend only regular follow-ups without the brace treatment. Male adolescent at Risser stage 1 have a lot of potential for growth and for male adolescents at Risser stage 1 or 2 with 20 degrees Cobb's angle, I recommend the brace treatment.

2. There are lots of debates about the results of Charleston and Providence braces treatment with Janicki et al. [1], insisting that the brace treatment is effective, while Wiemann et al. [2], insist that it is not effective. Although I do not have academic evidence yet, I personally think that applying the Providence brace treatment at night and the Charlstone brace treatment during the day might be a way of increasing patient compliance.

3. The Lenke classification [3] is well sorted and effective in fusion level decision, but is too complex. The King classification [4] is simple to use, but the inter-observer variance is large. The Peking Union Medical College (PUMC) classification [5] is simple and useful, but it is not commonly used worldwide. As each of the classifications has its strengths and weaknesses, I personally prefer the King classification. Most of the studies cited in this paper used the King classification or some classification similar to the King classification.

\section{Conflict of Interest}

No potential conflict of interest relevant to this article was reported.

\section{References}

1. Janicki JA, Poe-Kochert C, Armstrong DG, Thompson GH. A comparison of the thoracolumbosacral orthoses and providence orthosis in the treatment of adolescent idiopathic scoliosis: results using the new SRS inclusion and assessment criteria for bracing studies. J Pediatr Orthop 2007;27:369-74.

2. Wiemann JM, Shah SA, Price CT. Nighttime bracing versus observation for early adolescent idiopathic scoliosis. J Pediatr Orthop 2014;34:603-6.

3. Lenke LG, Betz RR, Clements D, et al. Curve prevalence of a new classification of operative adolescent idiopathic scoliosis: does classification correlate with treatment? Spine (Phila Pa 1976) 2002;27:604-11.

4. King HA, Moe JH, Bradford DS, Winter RB. The selection of fusion levels in thoracic idiopathic scoliosis. J Bone Joint Surg Am 1983;65:1302-13.

5. Qiu G, Li Q, Wang Y, et al. Comparison of reliability between the PUMC and Lenke classification systems for classifying adolescent idiopathic scoliosis. Spine (Phila Pa 1976) 2008;33:E836-42. 